\title{
Persistent Elastase/Proteinase Inhibitor Imbalance during Prolonged Ventilation of Infants with Bronchopulmonary Dysplasia: Evidence for the Role of Nosocomial Infections
}

\author{
H. WALTI, C. TORDET, L. GERBAUT, P. SAUGIER, G. MORIETTE, AND J. P. RELIER \\ Neonatal Intensive Care Unit, Port-Royal Maternity, Paris [H.W., G.M., J.P.R., P.S.]; CNRS, Cellular Biology \\ Center, Ivry [C.T.]; and Department of Biochemistry, Hopital St Vincent-de-Paul, Paris [L.G.] France
}

\begin{abstract}
Acute imbalance between elastase and $\alpha-1-$ proteinase inhibitor $(\alpha 1 \mathrm{Pi})$ may contribute to the development of bronchopulmonary dysplasia (BPD). The question of whether such an imbalance persists in BPD infants still requiring mechanical ventilation after 4 wk of life has not been previously addressed. We studied 14 infants still on mechanical ventilation at 4 wk of age: nine had BPD and five did not. Weekly ( 4 to 9 wk) serum and bronchoalveolar lavage (BAL) specimens were taken. $\alpha 1 \mathrm{Pi}$ and $\alpha-2$-macroglobulin were measured in serum and BAL by immunoturbidimetric assay. BAL elastase activity was measured by cleavage of a synthetic substrate and expressed as ng of porcine pancreatic elastase equivalent. Infants with BPD had higher levels of serum $\alpha 1 \mathrm{Pi}$ and $\alpha$-2-macroglobulin than those without BPD. In contrast, the corresponding BAL levels were either similar or even decreased $(\alpha 1 \mathrm{Pi})$. Moreover, there was a 3-fold increase in elastase-1Pi imbalance expressed as the BAL ng of porcine pancreatic elastase equivalent/2 $\alpha 1 \mathrm{Pi}$ ratio. The role of nosocomial infections was evident in a subgroup of 11 infected BAL aspirates in BPD infants. In such cases we found a 3-fold increase in the $\mathrm{BAL}$ ng of porcine pancreatic elastase equivalent $/ \alpha 1 \mathrm{Pi}$ ratio as compared to 35 noninfected $\mathrm{BAL}$ in BPD infants. These data suggest a persistent alveolitis with imbalance between elastase and proteinase inhibitors in prolonged severe BPD. Such an imbalance is, in part, explained by a local destruction and/or inactivation of $\alpha 1 \mathrm{Pi}$. Our results also emphasize the increase in proteolysis with nosocomial pneumonia. (Pediatr Res 26: 351-355, 1989)
\end{abstract}

\section{Abbreviations}

$\alpha 1 \mathrm{Pi}, \alpha-1$-proteinase inhibitor

$\alpha 2 \mathrm{M}, \alpha$-2-macroglobulin

AM, alveolar macrophage

BAL, bronchoalveolar lavage

BPD, bronchopulmonary dysplasia

MV, mechanical ventilation

NPE, ng of porcine pancreatic elastase equivalent

PMN, Polymorphonuclear

PMSF, phenylmethylsulfonyl fluoride

RDS, respiratory distress syndrome

SAPNA, N-succinyl-L(alanyl 3 )-P-nitroanilide in $\mathbf{N}$ methyl-pyrrolidine

Received January 4, 1989; accepted April 21, 1989.

Correspondence and reprint requests H. Walti, M.D., Service de Médecine Néonatale, Hôpital Port Royal, 123 bd de Port Royal, 75674, Paris, France.

H.W. was supported by a grant from la Fondation pour la recherche médicale, Paris, France.
Premature infants with acute neonatal lung injury, usually RDS, may develop neonatal chronic pulmonary disease, of which the most common form is BPD. The exact pathogenesis of BPD is unresolved, however, many recent reports emphasize the importance of inflammatory events $(1,2)$. Histologic and cytologic studies of infants with RDS have shown an early and significant alveolitis which consists of inflammatory cells (PMN and AM) (1-4). This alveolitis is prolonged in infants with RDS who develop BPD (3). Activation of these cells within the lung $(5,6)$ leads to secretion and release of many products that alter function or damage lung cells and connective tissues. The potential role in the pathogenesis of BPD of one of these products, the main proteolytic enzyme elastase, has recently been demonstrated in infants with RDS between the 2 nd and the 28 th $\mathrm{d}$ of postnatal age. Two studies reported an elevation of BAL elastase levels, coupled with low BAL levels of the main proteinase inhibitor $\alpha 1 \mathrm{Pi}$. This results in an imbalance between elastase and $\alpha 1 \mathrm{Pi}(1$, 2). Moreover, this elastase-proteinase inhibitor imbalance has been associated with the destruction of lung connective tissue and the resultant fibrotic changes characteristic of BPD (7). The question of whether such a BAL imbalance persists in BPD infants still requiring MV after $28 \mathrm{~d}$ of life has not been addressed. Furthermore, prolonged BPD is often associated with nosocomial lung infections, and the role of such infections in elastolytic damage has been recently emphasized in both acute and chronic lung disease $(8,9)$. We designed a prospective study to answer the following questions: 1 ) Is severe BPD that still requires mechanical ventilation at $\mathrm{d} 28$ associated with elastase-proteinase inhibitor imbalance? 2) Does MV per se result in such an imbalance? 3) Do nosocomial infections play a role in that imbalance?

\section{MATERIALS AND METHODS}

Patient groups. Fourteen low birth wt infants with or without $\mathrm{BPD}$, who still required MV at $28 \mathrm{~d}$ of age, were enrolled in the study. The BPD group consisted of nine infants who fulfilled all the following criteria: 1) Primary respiratory disorder requiring MV with supplemental oxygen from birth and for at least $3 \mathrm{~d}$ (five infants had RDS, two pneumonia, and two severe wet lung disease); 2) chronic respiratory distress at $28 \mathrm{~d}$ of age, requiring $\mathrm{MV}$ and supplemental oxygen to maintain $\mathrm{PaO}_{2}>60$ torr and $\mathrm{PaCO}_{2}<45$ torr; 3) chest $\mathrm{x}$-ray $28 \mathrm{~d}$ postnatally consistent with the diagnosis of BPD stage III or IV according to Northway et al. (10). Five infants without BPD but with prolonged MV served as a control group. These infants fulfilled all the following criteria: 1) No primary respiratory disorder, but MV from birth for at least $3 \mathrm{~d}$ without supplemental oxygen (the five infants enrolled had MV because of their low birth wt);2) absence of significant 
chronic respiratory distress, as described above, but necessity for MV (e.g. for apneas) at $28 \mathrm{~d}$ of age; 3) normal chest x-ray at 28 $\mathrm{d}$ of age.

Study design. After informed consent was obtained from the parents, the 14 patients were studied weekly, from the 4th to the 9 th wk of life or until extubation. We performed 1) BAL; 2) blood sampling; 3) recording of clinical data; 4) diagnosis of nosocomial pneumonia. To reduce the potential influence of adult blood transfusion on the results, no measurements were performed for a period of $48 \mathrm{~h}$ after transfusion.

Bronchoalveolar lavage. Tracheal effluents were obtained using a standardized technique of BAL $(1,2)$, by the same physiotherapist as follows: $1 \mathrm{~mL}$ of sterile $0.9 \% \mathrm{NaCl}$ was gently instilled into the endotracheal tube. Then the infant was ventilated for a few breaths and deep endotracheal aspiration performed using a no. 6 French catheter. To rinse the side wall of the catheter, 1 $\mathrm{mL}$ of sterile $0.9 \% \mathrm{NaCl}$ was then aspirated. The product of four lavages at 30 -min intervals was collected in a sterile mucus extractor. A total of $4 \mathrm{~mL}$ of sterile $0.9 \% \mathrm{NaCl}$ was instilled. Mean amount of tracheal effluent was not different between groups $(3.35 \pm 0.09 \mathrm{~mL}$ for controls and $3.42 \pm 0.05 \mathrm{~mL}$ for BPD). Each BAL was refrigerated at $4^{\circ} \mathrm{C}$ before processing and centrifuged at $1500 \times g$ for $15 \mathrm{~min}$ at $4^{\circ} \mathrm{C}$ as soon as possible. The cell free supernatant was frozen at $-20^{\circ} \mathrm{C}$ until analysis.

Blood samples. One $\mathrm{mL}$ of blood was drawn by venous puncture and plasma was separated by centrifugation and frozen within $2 \mathrm{~h}$ after sampling until analysis.

Clinical data were recorded in order to assess requirement of oxygen $\left(\mathrm{FiO}_{2}\right)$ and of $\mathrm{MV}$, expressed as a ventilatory index (mean airway pressure. $\mathrm{FiO}_{2} / \mathrm{PaO}_{2}$ ).

Diagnosis of nosocomial pneumonia was made when all the following criteria were present: 1) A dominant pathogenic microorganism and altered PMN in routine tracheal aspirate cultures; 2) clinical and radiologic signs of pneumonia; 3) laboratory markers of infection (abnormal values for white blood count, Creactive protein, and fibrinogen).

$B A L$ elastase activity was determined by the cleavage of a synthetic substrate, SAPNA, as described by Bieth et al. (11). Briefly, $100 \mu \mathrm{L}$ of BAL were reacted with $30 \mu \mathrm{L}$ of $125 \mathrm{mM}$ SAPNA in $900 \mu \mathrm{L}$ buffer $(200 \mathrm{mM}$ Tris- $\mathrm{HCl} \mathrm{pH} 8.3$ with 10 $\mathrm{mM} \mathrm{CaCl}$ ). After $1 \mathrm{~h}$ incubation at $37^{\circ} \mathrm{C}$, the reaction was stopped on ice and the change in optical density at $410 \mathrm{nM}$ measured using an LKB 4050 spectrophotometer (Biochrom Ltd, Cambridge, England). Elastase activity was then compared to the cleavage of SAPNA by porcine pancreatic elastase in the same buffer containing $1 \mathrm{mg} / \mathrm{mL}$ of BSA. Measurements were done in duplicate. Elastase activity was expressed as NPE divided by BAL albumin. Serine-elastase inhibitable activity was determined by the change in optical density between the initial elastase activity and that after preincubation of $100 \mu \mathrm{L}$ of BAL with 0.01 $\mathrm{mM}$ PMSF, for $1 \mathrm{~h}$ at $37^{\circ} \mathrm{C}$. Metallo-elastase inhibitable activity was similarly determined after preincubation with 5 mM EDTA.

$B A L$ and serum albumin and proteinase inhibitors. We measured BAL albumin as an indicator of persistent increase in pulmonary epithelial permeability and also to standardize BAL measurements of elastase and proteinase inhibitors. Albumin and two main proteinase inhibitors, $\alpha 1 \mathrm{Pi}$ and $\alpha 2 \mathrm{M}$, were assayed by immunoturbidimetry in both BAL and serum specimens using a Kone Progress Autoanalyser (Kone Instrument, Helsinki, Finland). Samples of 2, 12, and $24 \mu \mathrm{L}$ (for albumin, $\alpha 1 \mathrm{Pi}$ and $\alpha 2 \mathrm{M}$, respectively) of serum diluted 1:50 in PBS pH 7.4 or of undiluted BAL were mixed with $100 \mu \mathrm{L}$ of a $45 \mathrm{~g} / \mathrm{L}$ dilution of polyethylene glycol in PBS and a 1:6 dilution of appropriate antiserum. Standard curves were prepared by serial dilutions of the $\mathrm{N}$ protein standard. The lowest detectable concentrations were $5 \mu \mathrm{g} / \mathrm{mL}$ for albumin, $2.5 \mu \mathrm{g} / \mathrm{mL}$ for $\alpha 1 \mathrm{Pi}$ and $1 \mu \mathrm{g} / \mathrm{mL}$ for $\alpha 2 \mathrm{M}$.

$B A L N P E / 2 \alpha 1+P i$ ratio. To express the imbalance between elastase and the most important proteinase inhibitor, $\alpha 1 \mathrm{Pi}$, and because $2 \mathrm{mg} \alpha 1 \mathrm{Pi}$ is required to neutralize each $\mathrm{mg}$ of elastase, we used their ratio expressed as NPE/2 $\mu \mathrm{g} \alpha 1 \mathrm{Pi}$ as previously suggested by Ogden et al. (2).

Chemical reagents. Porcine pancreatic elastase and SAPNA were obtained from Biosys, Compiègne, France; PMSF and BSA from Sigma Chemical Co., St. Louis, MO; EDTA and buffers from Merck, Darmstadt, FRG; antibodies and standard proteins from Orimbio, Paris, France.

Data analysis. The data are given as mean $\pm \mathrm{SD}$ when distributed normally, otherwise as median and range. In our five control infants, values at increasing postnatal ages were not statistically different. We therefore combined the 14 corresponding values. Differences between groups were evaluated with analysis of variance if the data were normally distributed, or with nonparametric tests: Mann-Whitney for unpaired values and Wilcoxon signed rank for paired values, if they were not. $p<0.05$ was taken as significant.

\section{RESULTS}

Patient data. The two groups, BPD $(n=9)$ and control $(n=$ $5)$, had similar birth wt and gestational ages. However, clinical evolution, as shown by requirements at d 1, and wk 4 and 8 , of oxygen, $\mathrm{FiO}_{2}$, and $\mathrm{MV}$, expressed as a VI, were different (Table 1).

Serum and BAL albumin. Serum albumin levels were not significantly different between control and BPD infants at any sampling time. In contrast, weekly BAL albumin levels were increased in BPD infants. The difference was significant $(p<$ 0.05 ) only at wk 4 when the median (range) was $103 \mathrm{mg} / \mathrm{L} \mathrm{(33-}$ 184) in BPD infants, in comparison to the overall median (range) $32 \mathrm{mg} / \mathrm{L} \mathrm{(1.4-67)} \mathrm{in} \mathrm{control} \mathrm{infants.} \mathrm{However,} \mathrm{the} \mathrm{latter} \mathrm{value}$ was not significantly different from the overall median (range) of $47 \mathrm{mg} / \mathrm{L}$ (9-462) for the BPD infants.

Serum and $B A L$ proteinase inhibitor. Table 2 shows that weekly serum levels of the two proteinase inhibitors $\alpha 1 \mathrm{Pi}$ and $\alpha 2 \mathrm{M}$ were increased in BPD infants as compared to controls. Increases were significant at wk 9 for $\alpha 1 \mathrm{Pi}$ and wk 5 and 6 for $\alpha 2 \mathrm{M}$, and also for the 46 overall $\alpha 1 \mathrm{Pi}$ values. In contrast, the weekly BAL proteinase inhibitor/albumin ratios, in BPD infants appear slightly decreased. However, this decrease was significant only for the 46 overall $\alpha 1 \mathrm{Pi}$ values (Table 2).

$B A L N P E$ specific activity and $B A L N P E / 2 \alpha 1 P i$ ratio. Compared to controls, weekly NPE specific activity in BAL was slightly increased in BPD infants (Table 3 ). This was significant at wk 9 , but not over the whole study period. Nonetheless, there was a 3-fold increase in the BAL NPE/2 $\alpha 1 \mathrm{Pi}$ ratio in BPD infants as compared to controls. This was significant at wk 7,8 , 9 , and for all the 46 BPD results combined.

In 31 of $46 \mathrm{BAL}$ samples in BPD infants, we were able to characterize the cellular origin(s) of this elastase activity. PMSFinhibitable activity (or serine-elastase activity) was detected in 29 of 31 BAL samples [52\% (0-87) of total activity] and the percentage was greater $(p<0.05)$ than EDTA-inhibitable activity (or metallo-elastase activity) which was detected in 22 of $31 \mathrm{BAL}$ samples [28\% (0-100) of total activity].

Results in subgroup of infected BPD infants. Eleven of the 46 samples in BPD infants were taken during a nosocomial infection as defined above. The results of these 11 samples were combined and compared to the 35 combined results of noninfected BPD infants and to the 14 combined results of the control group. None of the five infants enrolled in the control group had nosocomial infections at the time of samplings. There were no differences in serum levels of albumin and proteinase inhibitors between those subgroups. In the infected BPD subgroup, the albumin level in BAL was elevated, as compared to control group (Table 4). BAL $\alpha 1 \mathrm{Pi}$, but not BAL $\alpha 2 \mathrm{M}$, was significantly decreased as compared to control group. The BAL NPE/albumin ratio was increased in the infected $\mathrm{BPD}$ subgroup, as compared to control group. Moreover, there was a 7-fold increase in the $\mathrm{NPE} / 2 \alpha 1 \mathrm{Pi}$ ratio in the infected BPD subgroup as compared to 
Table 1. Birth wt $(B W)$, gestational age $(G A)$, and clinical condition of BPD and control infants on $d 1$, and wk 4 and 8 of age [Mean $(S D)]$

Clinical Condition

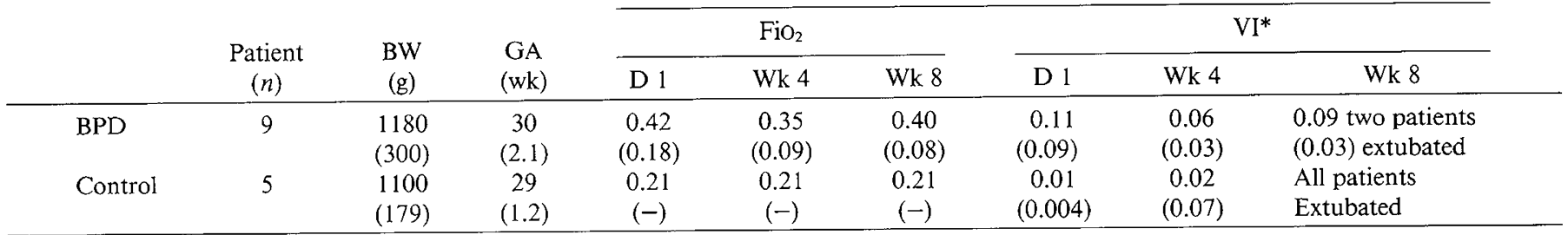

* Ventilatory index $=\left(\right.$ mean airway pressure $\left.\left.\times \mathrm{FiO}_{2}\right) / \mathrm{PaO}_{2}\right)$.

Table 2. Serum and BAL $\alpha 1 P i$, and $\alpha 2 M$ in control and BPD infants at 4 to 9 wk of age*

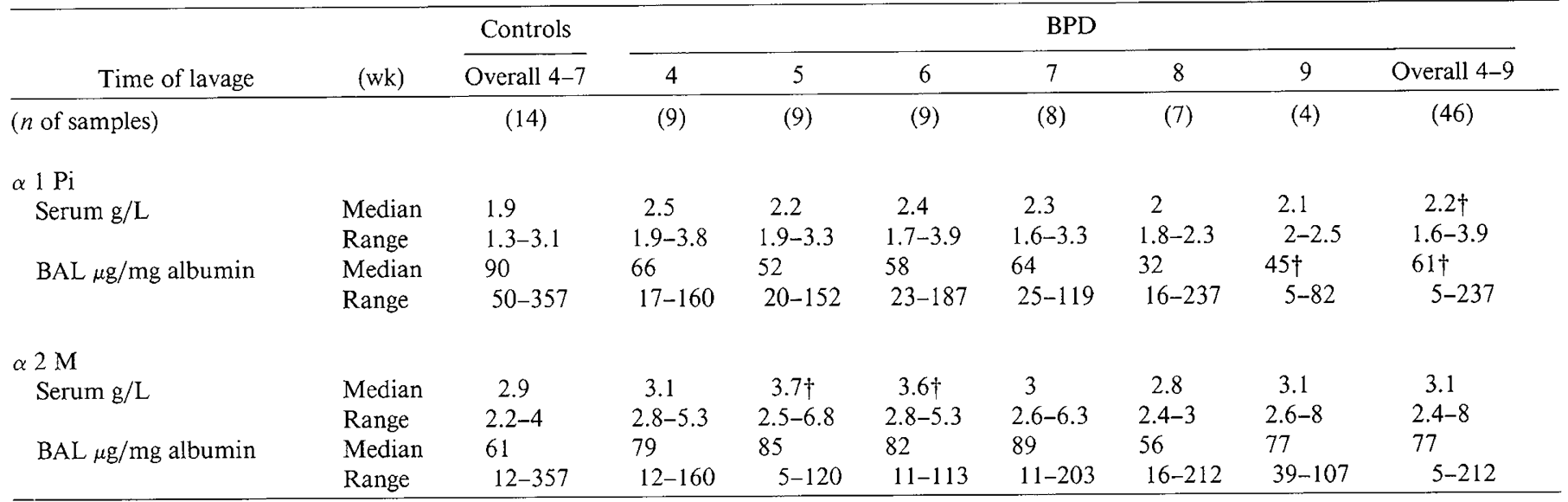

* Median values for each week and for the whole study period in the BPD infants are compared to median values for the whole period in control infants.

$\dagger p$ versus control values $<0.05$.

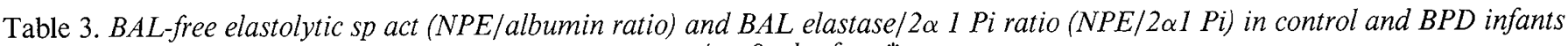
at 4 to 9 wk of age*

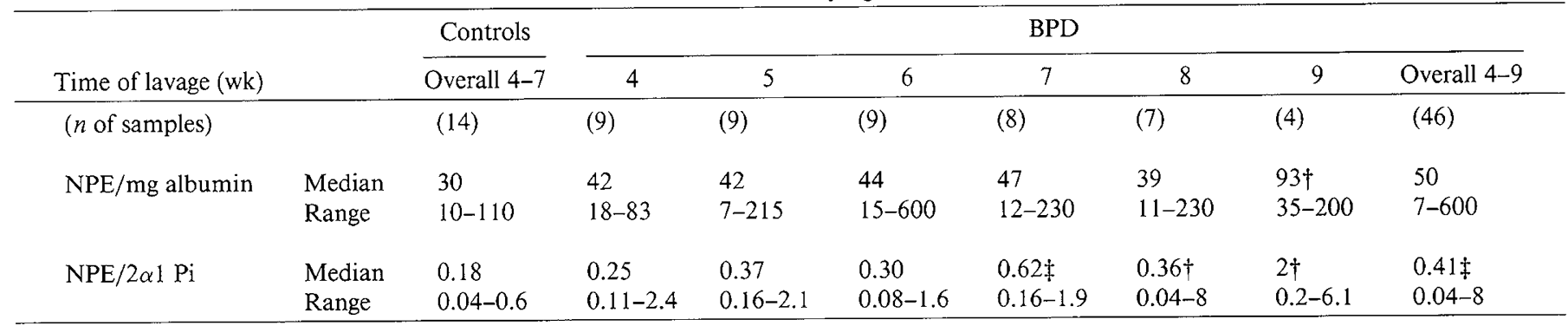

* Results are expressed as in Table 2.

$p$ versus control values, $\uparrow<0.05, \ddagger 0.01$.

the control group and over 3-fold increase as compared to the noninfected BPD subgroup. In 10 of the 11 BAL samples of the infected BPD subgroup, we were able to characterize the cellular origin(s) of the elastase activity. Results are listed in Table 5. PMSF-inhibitable activity (serine-elastase activity) was detected in all the BAL specimens and at a higher percentage $(p<0.05)$ than EDTA-inhibitable activity (or metallo-elastase activity) which was detected only in six samples.

\section{DISCUSSION}

We report evidence of a persistent imbalance between elastase and proteinase inhibitors in severe BPD which still required MV at 4 wk of age. These results support the view that subacute pulmonary inflammation plays an important role in the development of BPD. According to histological and cytological descriptions $(1-4,12)$ alveolitis is present in BPD, in both early and late stages. Many recent reports provide data concerning inflammatory cells in the tracheal aspirate from infants with RDS. They all report that PMN is the predominant cell type in the early stages (1st to 4th d) of RDS and appears before AM in the lung (1-4), but they disagree about the sequence of cytologic events during the early development of BPD (1st to 4 th wk). Merritt et al. (3) found that AM was the predominant inflammatory cell type after the $1 \mathrm{st}$ wk of evolution, whereas Ogden et al. (2) found the PMN count elevated until 5 wk of life. Clement et al. (6) suggest that even in older infants with BPD (4 mo of age), who no longer require $\mathrm{MV}, \mathrm{AM}$ is the predominant cell type and appears to be activated, as in the early stage of BPD (5). In neonatal $\operatorname{RDS}(1)$, and in adult $\operatorname{RDS}(13,14)$, the predominant elastase activity is inhibitable by PMSF (serine-elastase), and is demonstrably of PMN origin (PMN-elastase). In chronic pulmonary injury (15), the predominant activity may be inhibitable by EDTA (metallo-elastase), which would probably be of AM origin.

Our results confirm that both PMSF- and EDTA-inhibitable 
activities are present in BPD, but the PMSF-inhibitable activity (serine-elastase or PMN-elastase) is the predominant one, even in the infected BPD subgroup. Our observations (Table 5, patients 3, 6, and 7) substantiate those of Bruce et al. (9), who reported the presence of predominantly PMSF-inhibitable activity in BAL of patients with cystic fibrosis chronically infected with Pseudomonas aeruginosa, a bacterium that has been demonstrated to produce a metallo-elastase (EDTA-inhibitable) activity (16). Nevertheless, the role of AM, particularly if activated, may be of a great importance. The AM appears to be able to internalize the PMN elastase (17), and a slow release of active enzyme from this reservoir may be one of the mechanisms contributing to the modulation of proteolysis (18).

Table 4. Effect of nosocomial infections on albumin, proteinase inhibitors $(\alpha 1$ Pi, $\alpha 2 M)$, free elastolytic specific activity (NPE/

albumin), and NPE/2 $\alpha 1$ Pi ratio in bronchoalveolar lavage

(BAL); values obtained from control infants (14 samples) are compared to those obtained from BPD infants when infected (11 samples) or not ( 35 samples)

\begin{tabular}{|c|c|c|c|}
\hline & \multirow[b]{2}{*}{ Control } & \multicolumn{2}{|c|}{ BPD } \\
\hline & & Noninfected & Infected \\
\hline ( $n$ of BAL samples) & (14) & (35) & $(11)$ \\
\hline \multicolumn{4}{|l|}{ Albumin (mg/L) } \\
\hline Median & 32 & 46 & $52^{*}$ \\
\hline Range & $1.4-67$ & $9-200$ & $22-462$ \\
\hline \multicolumn{4}{|c|}{$\alpha 1 \mathrm{Pi}(\mu \mathrm{g} / \mathrm{mg}$ albumin $)$} \\
\hline Median & 90 & 62 & $56 \dagger$ \\
\hline Range & $50-360$ & $16-237$ & $5-82$ \\
\hline \multicolumn{4}{|c|}{$\alpha 2 \mathrm{M}(\mu \mathrm{g} / \mathrm{mg}$ albumin $)$} \\
\hline Median & 61 & 67 & 82 \\
\hline Range & $12-357$ & $5-212$ & $5-160$ \\
\hline \multicolumn{4}{|l|}{$\mathrm{NPE} / \mathrm{mg}$ albumin } \\
\hline Median & 30 & 47 & $59 \dagger$ \\
\hline Range & $10-110$ & $7-236$ & $18-215$ \\
\hline \multicolumn{4}{|l|}{$\mathrm{NPE} / 2 \alpha 1 \mathrm{Pi}$} \\
\hline Median & 0.18 & $0.35 \dagger \S$ & $1.25 \ddagger$ \\
\hline Range & $0.04-0.6$ & $0.04-2.4$ & $0.14-6.1$ \\
\hline
\end{tabular}

$p$ versus control values, $*<0.05, \dagger<0.01, \ddagger<0.001$.

$\S p$ versus infected values, $<0.01$.
In agreement with the results of Ogden et al. (2), the increasing free elastolytic activity we found in BPD infants was not associated with increasing levels of proteinase-inhibitors. Moreover, the BAL $\alpha 1 \mathrm{Pi}$ /albumin ratio is significantly decreased in BPD infants as compared to controls. Two pieces of evidence support the hypothesis of local destruction and/or inactivation of $\alpha 1 \mathrm{Pi}$. First, no decrease but rather an increase of serum $\alpha 1 \mathrm{Pi}$, and $\alpha 2 \mathrm{M}$ was found in BPD infants as compared to controls. These results are in agreement with those of Ogden et al. (2) and suggest that very low birth wt infants are able to increase production of acute phase proteins during pulmonary inflammation. Second, the inability of BPD infants to increase BAL $\alpha 1 \mathrm{Pi}$ is not explained by low transudation rate. Indeed the serum $\alpha 1 \mathrm{Pi}$ level clearly modulates lung level of $\alpha 1 \mathrm{Pi}$, a $50000 \mathrm{D}$ protein, and it is well known that increased pulmonary capillary permeability in BPD facilitates access of serum proteins to the alveoli (19). This is clearly demonstrated in our study by increased levels of BAL albumin in BPD infants and also by the detection of significant levels of BAL $\alpha 2 \mathrm{M}$, a $725000 \mathrm{D}$ protein, which is normally not present in healthy adult lung (20). In contrast significant levels of $\alpha 2 \mathrm{M}$ have been detected in adult inflamed lung (21) and also in newborn lung during prolonged MV (22). The low antigenic level of BAL $\alpha 1 \mathrm{Pi}$ we found can be explained by oxidative and/ or proteolytic destruction of the protein. Indeed, simple oxidative inactivation of $\alpha 1 \mathrm{Pi}$ by a reactive oxygen metabolite generated by PMN has been demonstrated (23). Inactivation of $\alpha 1 \mathrm{Pi}$ is explained by oxidation of an active site methionine residue (23), which renders this protein susceptible to proteolytic digestion (24).

Inactivated oxidized $\alpha 1 \mathrm{Pi}$ and a proteolytic product of degradation have been found in the early stage of BPD (1) and also in cystic fibrosis (25). As oxidation of $\alpha 1 \mathrm{Pi}$ reduces the binding capacity for PMN elastase 2000-fold (26), and because we measured only antigenic levels of $\alpha 1 \mathrm{Pi}$, detecting both native and oxidized $\alpha 1 \mathrm{Pi}$ as well as $\alpha 1 \mathrm{Pi}$ bound to elastase, we have probably underestimated the imbalance between elastolytic activity and active $\alpha 1 \mathrm{Pi}$.

Our results also emphasize the role of nosocomial infection in the course of BPD. A dramatic increase in elastase-proteinase inhibitor imbalance was shown in a subgroup of infected BPD lavages. These results support those of other authors, especially in cystic fibrosis $(9,25)$. Chronic infection of the lung in cystic fibrosis, with bacteria such as Staphylococcus aureus and $P$. aeruginosa, has been shown to participate in proteolysis of lung connective tissue $(9,25)$, and in such cases the mechanism of elastase-proteinase inhibitor imbalance has been shown to be the same as discussed above (26). The well-known role of acute

Table 5. Sputum bacteriology, sp act (NPE/albumin ratio), and inhibition characteristics of elastase in 11 BAL samples from infected BPD infants*

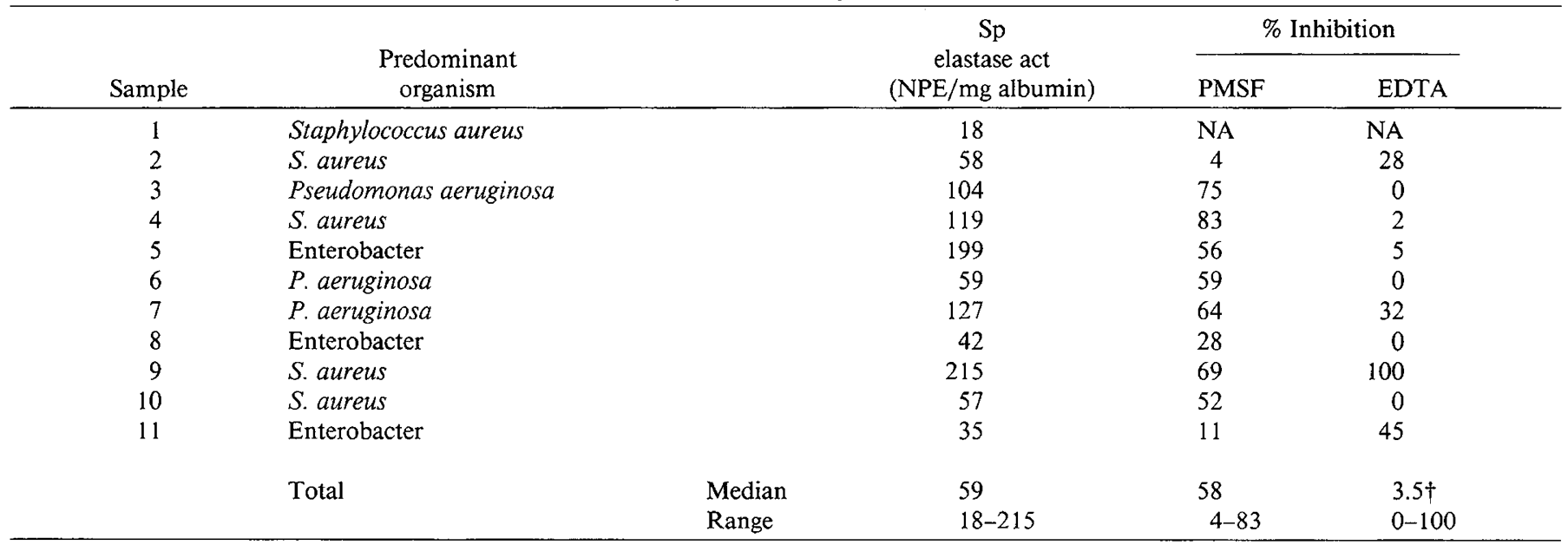

\footnotetext{
* PMSF, phenylmethylsulfonyl fluoride; NA, not assayed. $\dagger p<0.05$ between EDTA and PMSF inhibition.
} 
nosocomial infection in the progression of BPD must be explained by increase in proteolytic destruction of the lung tissue.

Our study suggests an important role for elastase-proteinase inhibitor imbalance in the prolonged course of BPD. The development of a routine assay (27) for detection of such an imbalance in serum and/or BAL could help in the management of BPD infants, especially in cases of nosocomial infection.

Acknowledgments. The authors acknowledge the help of $\mathrm{J}$. Baudouin, physiotherapist. We thank O. Strickland for stylistic review of the manuscript and $\mathrm{M}$. Blanchard for technical assistance.

\section{REFERENCES}

1. Merritt TA, Cochrane CG, Holcomb K, Bohl B, Hallman M, Strayer D Edwards DK, Gluck L 1983 Elastase and alpha 1-proteinase inhibitor activity in tracheal aspirates during respiratory distress syndrome. $\mathbf{J}$ Clin Invest 72:656-666

2. Ogden BE, Murphy SA, Saunders GC, Pathak D, Johnson JD 1984 Neonatal lung neutrophils and elastase/proteinase inhibitor imbalance. Am Rev Respir Dis 130:817-821

3. Merritt TA, Stuard ID, Puccia J, Wood B, Edwards DK, Finkelstein J, Shapiro DL 1981 Newborn tracheal aspirate cytology: classification during respiratory distress syndrome and bronchopulmonary dysplasia. J Pediatr 98:949956

4. Jackson JC, Chi EY, Wilson CB, Truog WE, Teh EC, Hodson WA 1987 Sequence of inflammatory cell migration into lung during recovery from hyaline membrane disease in premature newborn monkeys. Am Rev Respir Dis 135:937-946

5. Irving LB, Jordana M, O'Brodovitch H, Gauldie J 1986 Alveolar macrophage activation in bronchopulmonary dysplasia. Am Rev Respir Dis 133:A207(abstr)

6. Clement A, Chadelat K, Sardet A, Grimfeld A, Tournier G 1988 Alveolar macrophage status in bronchopulmonary dysplasia. Pediatr Res 23:470-473

7. Bruce M, Wedig KE, Jentoft N, Martin K, Cheng PW, Boat TF, Fanaroff AA 1985 Altered urinary excretion of elastin cross-links in premature infants who develop bronchopulmonary dysplasia. Am Rev Respir Dis 131:568572

8. Abrams WR, Fein AM, Kucich U, Kueppers F, Yamada H, Kuzmowycz $\Upsilon$, Morgan L, Lippmann M, Golberg SK, Weinbaum G 1984 Proteinase inhibitory function in inflammatory lung disease I. Acute bacterial pneumonia. Am Rev Respir Dis 129:735-741

9. Bruce M, Poncz L, Klinger JD, Stern RC, Tomashefski JF, Dearborn DG 1985 Biochemical and pathologic evidence for proteolytic destruction of lung connective tissue in cystic fibrosis. Am Rev Respir Dis 132:529-535

10. Northway WH, Rosan RC, Porter DY 1967 Pulmonary disease following respirator therapy of hyaline membrane disease, bronchopulmonary dysplasia. N Engl J Med 276:357-368

11. Bieth J, Spiesse B, Wermuth CG 1974 The synthesis and analytical use of a highly sensitive and convenient substrate of elastase. Biochem Med 11:350 357

12. Stocker JT 1986 Pathologic features of long-standing "healed" broncho-pulmonary dysplasia: A study of 28 - to 40 -month-old infants. Hum Pathol 17:943-961

13. Lee CT, Fein AM, Lippmann $M$, Holtzaaman $H$, Kimbel $P$, Weinbaum $G$ 1981 Elastolytic activity in pulmonary lavage fluid from patients with adult respiratory distress syndrome. N Engl J Med 304:192-196

14. Mc Guire W, Spragg R, Cohen A, Cochrane CG 1982 Studies on the pathogenesis of the adult respiratory distress syndrome. J Clin Invest 69:543-553

15. Niederman MS, Fritts LL, Merrill WW, Fick RB, Matthay RA, Reynolds HY, Gee JBL 1984 Demonstration of a free elastolytic metallo enzyme in human lung lavage fluid and its relationship to alpha-1-antiprotease. Am Rev Respir Dis 129:943-947

16. Morihara K, Tsusuki H, Oda K 1979 Protease and elastase of Pseudomonas aeruginosa: inactivation of human plasma alpha-1 proteinase inhibitor Infect Immun 24:188-193

17. Campbell EJ, Wald MS 1983 Hypoxic injury to human alveolar macrophages accelerates release of previously bound neutrophil elastase. Am Rev Respir Dis 127:631-635

18. Mc Gowan SE, Stone PJ, Snider GL, Franzblau C 1984 Alveolar macrophage modulation of proteolysis by neutrophil elastase in extracellular matrix. Am Rev Respir Dis 130:734-739

19. Jefferies LG, Coates AL, O'Brodovitch H 1984 Pulmonary epithelial permeability in hyaline membrane disease. N Engl J Med 311:1075-1080

20. Gadeck JE, Fells GA, Zimmerman RL, Rennard SI 1981 Anti elastases of the human alveolar structures. J Clin Invest 68:889-898

21. Hunninghake GW, Gadeck JE, Kawanami O, Fernans VJ, Crystal RG 1979 Inflammatory and immune processes in the human lung and disease: evaluation by bronchoalveolar lavage. Am J Pathol 97:149-198

22. Bruce M, Martin RJ, Boat TF 1984 Concentrations of alpha-1-proteinase inhibitor and alpha-2 macroglobulin in serum and lung secretions of intubated infants. Pediatr Res 18:35-40

23. Johnson D, Travis J 1979 The oxidative inactivation of human alpha-1 proteinase inhibitor. Further evidence for methionine as the reactive center. J Biol Chem 254:4022-4026

24. Baumstark JS, Lee CT, Luby RJ 1977 Rapid inactivation of alpha-1-proteinase inhibitor (alpha-1-antitrypsin) by elastase. Biochim Biophys Acta 482:400411

25. Goldstein W, Döring G 1986 Lysosomal enzymes from polymorphonuclear leucocytes and proteinase inhibitors in patients with cystic fibrosis. Am Rev Respir Dis 134:49-56

26. Beatty K, Bieth J, Travis J 1980 Kinetics of association of serine proteinase with native and oxidized Alpha-1-proteinase inhibitor and alpha-1 antichymotrypsin. J Biol Chem 255:3931-3934

27. Suter S, Schaad UB, Tegner H, Ohhssan K, Desgrandchamps D, Waldwogel FA 1986 Levels of free granulocyte elastase in bronchial secretions from patients with cystic fibrosis: effect of antimicrobial treatment against Pseudomonas aeruginosa. J Infect Dis 153:902-909 